\title{
SOBRE A PERTINÊNCIA DO ESTUDO DE LETRAS CLÁSSICAS NO BRASIL CONTEMPORÂNEO
}

\author{
Flávio Ribeiro de Oliveira \\ frasp@iel.unicamp.br
}

O estudo de "letras clássicas" - ou simplesmente de "clássicas" - é o estudo do grego, do latim e dos textos (literários, filosóficos, historiográficos etc.) produzidos nessas línguas desde Homero até o fim do Império Romano. O grego ${ }^{1}$ e o latim são línguas mortas: nenhum povo as emprega hoje para a comunicação cotidiana ou para a produção de literatura.

Acredito que qualquer professor de grego ou latim em atividade hoje no Brasil já ouviu a questão "grego? Latim? Para que serve isso?". A essa questão - ora lançada a nós meio zombeteira, ora severamente crítica muitos reagimos com um enfadado olhar de superioridade ou com um suspiro de impaciência, sem nos dar o trabalho de responder (mais ao menos como Louis Armstrong, quando certa vez lhe perguntaram o que era o jazz: se você precisa fazer essa pergunta, nem vale a pena eu tentar explicar). Contudo, a questão é legitima: se devemos refletir com seriedade sobre a construção de um sistema público de educação voltado para os interesses maiores da sociedade que o financia, é preciso investigar se faz sentido, no Brasil do século XXI, ensinar clássicas. Notem que a questão não se coloca em termos de inclinações pessoais ou de gosto individual:

${ }^{1} \mathrm{O}$ grego que estudamos em Letras Clássicas não é o grego que se fala hoje na Grécia: este provém daquele, mas - simplificando um pouco - é tão diferente dele quanto, por exemplo, o italiano é do latim. 
quem nos interpela não admitirá respostas como "eu estudo clássicas porque gosto" ou "porque me dá satisfação pessoal". A questão é política: diz respeito à pertinência dos estudos clássicos no sistema educacional deste país.

Todos concordarão que a questão "para que ensinar clássicas?" não admite uma resposta absoluta, ao contrário de questões como "qual é a raiz quadrada de nove?": a resposta que se dará a ela depende do contexto histórico em que é formulada e dos pontos de vista de quem a formula e de quem a responde sobre o tipo de sociedade a que visamos e sobre o papel da educação na construção desse modelo de sociedade.

Para balizar a discussão, retomo o célebre ensaio que T. S. Eliot escreveu em 1932 sobre o tema: "Modern Education and the Classics". Esse texto é evocado com frequência por aqueles que defendem o estudo de clássicas - contudo, se fizermos um exame atento daquilo que o autor de fato afirma e extrairmos todas as consequências de seu arrazoado, chegaremos a conclusões pouco auspiciosas com relação à pertinência do ensino de clássicas no Brasil de hoje.

Eliot considera que podemos adotar três tipos de atitude no que se refere à educação. A primeira atitude é aquela que ele chama de liberal (é a atitude que predominava quando Eliot escreveu o ensaio - e, penso, predomina ainda hoje): no sistema liberal, o aluno tem liberdade para escolher o estudo daquelas disciplinas que lhe permitirem o desenvolvimento mais completo de suas aptidões naturais. A educação não é mera aquisição de fatos, de informações: é um processo de treinamento do intelecto para que, em determinadas áreas de atividade, o estudante seja capaz de resolver problemas de forma autônoma - quaisquer que sejam. Nesse percurso, ele pode seguir suas propensões naturais: alguns se desenvolvem e se realizam intelectualmente estudando grego e latim; outros podem obter o mesmo resultado estudando física, história medieval ou culinária: o conteúdo não importa; o que importa é o processo. É evidente que, se a nossa perspectiva com relação à educação for a liberal, o estudo do latim, do grego e dos textos escritos nessas línguas não é imprescindível na educação. Portanto, à questão “devemos estudar clássicas hoje?” o educador liberal responderá: não necessariamente. Pode-se estudar, pode-se não estudar: fica a gosto do freguês.

A segunda atitude é aquela que Eliot chama de radical. Ao contrário da atitude liberal, que não dá uma resposta definitiva à questão, a atitude radical lhe dá uma resposta peremptória (e é a resposta errada, segundo 
Eliot). A atitude radical é pragmática: se vou formar um médico, ele deve aprender tudo o que é necessário para que seja um bom médico - e nada mais. Do mesmo modo, um engenheiro terá de dominar todas as disciplinas que farão dele um bom engenheiro - e só. O grego e o latim são supérfluos na formação do engenheiro ou do médico. Muitos daqueles que hoje nos perguntam "para que serve o grego?" têm como pressuposto justamente essa atitude radical - e dessa perspectiva é muito difícil justificar o estudo de grego: de fato, o grego não serve para construir pontes ou para plantar soja.

T. S. Eliot considera, por fim, uma terceira atitude com relação ao estudo de clássicas: aquela que ele considera a atitude correta e que chama de ortodoxa. A educação ortodoxa é, para Eliot, a educação cristã. E, no quadro de uma educação cristã, o ensino de grego e latim é imprescindível: precisamos dele para preservar a cultura e os valores cristãos.

Eliot era cristão. Podemos compreender os motivos pelo qual defende o modelo educacional ortodoxo. Contudo, nossa discussão diz respeito ao Brasil de 2013. Seria possível aplicar o raciocínio e as conclusões de Eliot à nossa situação histórica e cultural? Para que possamos responder a essa questão, é necessário verificar para que tipo de sociedade Eliot propunha a educação ortodoxa - e com quais objetivos - e, em seguida, conferir se esse modelo de sociedade se assemelha ao nosso - e se os projetos que Eliot tinha para a sociedade em que vivia coincidem com os nossos.

Para Eliot, só havia duas possibilidades de civilização no mundo moderno: a civilização cristã e a civilização materialista marxista. Seu ensaio foi escrito em 1932, quinze anos depois da Revolução Russa e dez anos depois da fundação da União Soviética. Foi escrito antes de Auschwitz e antes de Hiroshima. Para o autor, o destino de nossa civilização se decidia no conflito de valores entre marxismo e cristianismo.

Com relação ao ensino de clássicas, a atitude marxista é a radical: ela é pragmática. No sistema soviético, por exemplo, a preocupação maior era formar engenheiros, médicos, físicos etc. que dominassem as disciplinas específicas indispensáveis para sua adequada formação. Nesse quadro, o grego e o latim são supérfluos, resquícios de uma cultura burguesa que deve ser superada. De fato, se pensarmos um pouco, podemos mencionar centenas de grandes helenistas e latinistas alemães, ingleses, franceses, norte-americanos etc. em atividade no século XX. Mas não teríamos tanta facilidade para nos lembrar do nome de um helenista ou latinista soviético importante.

Muito bem: essa era a posição de Eliot. Mas não podemos deixar de perguntar: e fora dessa dicotomia? Nosso caso particular - o Brasil de 2013 - está fora dela. Hoje, mais de 8o anos depois de Eliot ter escrito 
seu ensaio, vivemos numa cultura que não é nem marxista nem cristã: na história do século XX, nenhum dos dois modelos prevaleceu. Países em desenvolvimento, como o Brasil, enfrentam hoje problemas que Eliot não vislumbrava em 1932. Entre nós, hoje, e o Eliot de 1932 há a Segunda Guerra Mundial, a Shoa, as bombas atômicas, a Guerra Fria, o fim do império soviético, o fundamentalismo islâmico, o atentado de 11 de setembro... E, como elemento complicador, nosso país tem características próprias que Eliot não considerava: a diversidade étnica e cultural, a fragmentação do cristianismo em uma multiplicidade de seitas populistas e imediatistas, a (ainda lenta) ascensão de classes sociais que até recentemente viveram totalmente à margem da cidadania e do progresso econômico do país... Aquele debate que opõe civilização cristã e civilização marxista já não faz sentido para nós - a não ser na cabeça de uns poucos ideólogos fundamentalistas dos dois lados...

Ora, no mesmo ensaio T. S. Eliot respondeu à nossa pergunta - se faz sentido o estudo de clássicas numa cultura situada fora da dicotomia que opõe marxismo a cristianismo. Eliot foi explícito: se acaso o mundo evoluir por um outro caminho, fora dessa dicotomia... Tanto faz! Nesse caso, pouco importa se o grego e o latim se tornarem tão desconhecidos como o etrusco: já não faz a menor diferença; esse caso seria a barbárie e Eliot não se interessa por esse mundo ${ }^{3}$. Ora, bárbaro ou não, esse é o nosso mundo. Eliot não se interessa por ele, mas nós somos obrigados a nos interessar... Para Eliot, pouco importa se nós, no Brasil de 2013, estudamos grego e latim. Mas nós, que hoje vivemos num país sul-americano laico, cuja Constituição não é nem marxista nem cristã (em que pese o elemento cristão em nossa formação cultural) - nós ainda precisamos responder a esta pergunta: por que, neste país economicamente poderoso, mas devastado por desigualdades e injustiças sociais atrozes, deveríamos ensinar clássicas aos jovens? A atitude pragmática não responderia melhor a nossas necessidades mais prementes? Por que investir dinheiro público para pagar o salário de professores de grego e latim, quando uma parte significativa da população mal sabe ler e escrever, não tem saneamento básico, não tem acesso a um sistema de saúde decente? Não seria

3 Vale a pena reproduzir as palavras de Eliot: "It is quite possible, of course, that the future may bring neither a Christian nor a materialistic civilization. It is quite possible that the future may bring nothing but chaos or torpor. In that event, I am not interested in the future; I am only interested in the two alternatives which seem to me worthy of interest". Op. cit. pág 173: "é bem possível, é claro, que o futuro não traga nem uma civilização cristã, nem uma materialista. É bem possível que o futuro não traga nada senão caos ou torpor. Nesse caso, não estou interessado no futuro; estou interessado apenas nas duas alternativas que me parecem dignas de interesse" (tradução minha). 
melhor nos preocuparmos com a formação de bons médicos, biólogos, engenheiros? Como afirmei no início deste texto, a questão é legítima: nós, professores de clássicas, não temos o direito de nos furtar a ela.

Em 1981 o escritor Italo Calvino publicou em L'Espresso um texto que pode - acredito - orientar nossa reflexão: trata-se do ensaio "Italiani, vi esorto ai classici" 4 . Embora o problema que ocupava Calvino fosse um pouco diferente deste que nos ocupa agora, creio que algumas de suas conclusões podem se aplicar a nosso caso. As diferenças são basicamente duas. Em primeiro lugar, Calvino adota uma definição mais ampla de "clássico", que inclui não só os grandes textos gregos e latinos da antiguidade, mas também todas aquelas obras de qualidade superior que influenciaram de forma decisiva a história da literatura e do pensamento. Entre os "clássicos" estão, sim, Homero, Sófocles, Virgílio, Horácio - mas também Dante, Cervantes, Dostoiévski, Flaubert. A definição de Calvino não é fechada: ele admite que o conceito de "clássico" é flexível e varia conforme o leitor: cada um de nós tem seu conjunto de clássicos. Para alguns de nós Svevo será um clássico, para outros talvez não. Nesse aspecto, a atitude de Calvino é aquela que Eliot chamaria de "liberal": cada um tem o seu gosto e estabelece o seu próprio caminho. De fato, a atitude liberal não permite que fixemos uma política curricular rígida. Contudo, apesar da relativa maleabilidade do elenco dos autores clássicos, ele sempre incluirá, de forma incontestável, a maior parte dos autores gregos e latinos cujos textos foram preservados. Em nenhuma lista pessoal de clássicos podem faltar Homero, Platão, Horácio. Penso, portanto, que essa definição mais abrangente do clássico adotada por Calvino não impede nosso recurso a seu ensaio: seus clássicos incluem os nossos; suas conclusões podem muito bem valer para nós.

A segunda diferença é mais grave. Calvino pensa na leitura dos clássicos fora das estruturas institucionais de ensino. Na verdade, Calvino crê que devemos ler os clássicos apesar da escola5: a escola obriga à leitura de um certo número de clássicos; os clássicos, porém, não devem ser lidos por dever, e sim por livre escolha e por amor. Nesse ponto, penso que não podemos aplicar o raciocínio de Calvino a nossa realidade sócio-cultural. Ele se justifica apenas em civilizações de sólida tradição cultural, nas quais os indivíduos tenham outros meios, além da escola,

${ }^{4}$ Republicado mais tarde, com o título de "Perché leggere i classici", na coletânea Perché leggere i classici (Milano, Mondadori, 1995, págs. 5-13). É esta edição que cito aqui.

5 "Le scelte che contano sono quelle che avvengono fuori e dopo ogni scuola". Op. cit., pág. 9: "as escolhas que contam são aquelas que ocorrem fora e depois de cada escola" (tradução minha). 
de obter informações culturalmente relevantes. Não é o nosso caso. Hoje a paideia do brasileiro é propiciada, basicamente, pela televisão - e nossa televisão é, em geral, omissa no que diz respeito à formação cultural de seu público (para não dizer que é totalmente deformante...). Entre nós, se o aluno não aprender a ler e estudar os clássicos na escola, dificilmente o fará por iniciativa própria - e isso pelo mero fato de que, fora da escola, ele dificilmente ouvirá falar de Ésquilo ou de Propércio.

Portanto, se queremos que nossos alunos conheçam e apreciem os clássicos, devemos ensinar esses autores na escola (e não só na universidade: penso sobretudo no ensino básico). Entretanto nossa primeira questão continua sem resposta: é necessário, afinal de contas, que nossos alunos conheçam e apreciem os clássicos?

Creio que, por trás do paradoxo e da aparente tautologia com que conclui seu ensaio ${ }^{6}$, Calvino nos aponta um caminho. Ler os clássicos é melhor do que não lê-los porque tais leituras formam um homem melhor - não um engenheiro melhor, não um médico melhor, mas um homem melhor. São leituras "formative nel senso che danno una forma alle esperienze future, fornendo modelli, contenitori, ternini di paragone, schemi di classificazione, scale di valore, paradigmi di bellezza" 7 .

Penso que essa é a boa resposta. É a resposta que dá Platão à pergunta “por que estudar filosofia?": porque torna os homens melhores. E não no sentido pragmático: um marceneiro que estude filosofia não se tornará, por isso, um marceneiro melhor. Do mesmo modo, um médico que estude os clássicos não se tornará, só por isso, um médico melhor. Vai se tornar um homem melhor ${ }^{8}$. Temos aqui o velho ideal da formação humanística (hoje infelizmente superado - e mesmo em meios acadêmicos - pelo utilitarismo imediatista, pelo produtivismo obtuso).

6 "Non si creda che i classici vanno letti perché "servono" a qualcosa. La sola raggione che si può addurre è che leggere i classici è meglio che non leggere i classici". Op. cit., pág. 13: "não se creia que os clássicos devam ser lidos porque "servem" para alguma coisa. A única razão que se pode aduzir é que ler os clássicos é melhor do que não ler os clássicos” (tradução minha).

${ }_{7}$ Op. cit., pág. 6: "formativas no sentido de darem uma forma às experiências futuras, fornecendo modelos, recipientes, termos de comparação, esquemas de classificação, escalas de valor, paradigmas de beleza" (tradução minha).

${ }^{8}$ Sei que essa formulação pode parecer simplória, mas assumo o ônus: não há outro modo de dizê-lo. Não afirmo (e tal afirmação seria abjetamente elitista) que o homem que conhece os clássicos é melhor do que o homem que não os conhece: o ponto fundamental, para mim, é que para um mesmo homem conhecer os clássicos é melhor do que não conhecê-los. 
Portanto, minha resposta à legítima questão sobre a pertinência dos estudos clássicos no Brasil contemporâneo é, sem hesitação, "sim"9. E não penso que tenham seu lugar em nosso sistema educacional por algum privilégio intrínseco ou por alguma pretensa superioridade das letras clássicas sobre as outras áreas. O estudo dos clássicos tem seu lugar no plano mais abrangente de uma formação humanística completa, no qual os clássicos gregos e latinos são imprescindíveis - mas também o são, por exemplo, Dante, Shakespeare, Stendhal, Machado de Assis. E essa conclusão é válida - parece-me evidente - mesmo fora daquela perspectiva cristã de T. S. Eliot: minha perspectiva é a de uma educação humanista laica. Independentemente de crença religiosa ou de orientação política, o homem que vier a conhecer a Antígona de Sófocles, a República de Platão ou o Alienista de Machado de Assis se tornará um homem melhor - e isso pelo simples fato de poder participar daquilo que de melhor nossa cultura produziu. Tal possibilidade deve ser oferecida a todo homem: o contato com aqueles autores não pode ser privilégio de alguma elite. Portanto, acredito que podemos inverter a pergunta que motivou estas reflexões e retrucar: por que privar os jovens de conhecer os clássicos? Temos o dever de lhes propiciar mais do que o show de domingo da televisão.

\section{REFERÊNCIAS BIBLIOGRÁFICAS}

CALVINO, ITALO. Perché leggere i classici. Milano, Mondadori, 1995, págs. 5-13

ELIOT, T. S. Essays - Ancient \& Modern. London, Faber \& Faber, s.d., págs. 161-174

9 Sem detrimento, é evidente, da boa formação técnica de médicos, engenheiros, físicos etc.: a formação humanista e a formação técnica têm finalidades diferentes e não são excludentes. 